\title{
ORGANIZAÇÃO DA NAÇÃO E MONOPOLIZAÇÃO DO ENSINO PELO ESTADO: HOMOGENEIDADE CULTURAL E EXCLUSÃO SOCIORRACIAL (BRASIL, SÉCULOS XIX E XX)
}

\author{
ORGANIZATION OF THE NATION AND MONOPOLIZATION OF \\ EDUCATION BY THE STATE: CULTURAL HOMOGENEITY AND \\ SOCIO-RACIAL EXCLUSION (BRAZIL, 19TH \\ AND 20TH CENTURIES)
}

\begin{abstract}
ORGANIZACIÓN DE LA NACIÓN Y MONOPOLIZACIÓN DE LA ENSEÑANZA POR EL ESTADO: HOMOGENEIDAD CULTURAL Y EXCLUSIÓN SOCIO RACIAL (BRASIL, SIGLOS XIX Y XX)
\end{abstract}

Cynthia Greive Veiga ${ }^{I}$

Resumo O objetivo do artigo é discutir a monopolização do ensino pelo Estado e a imposição da homogeneidade cultural por meio da institucionalização das escolas públicas e obrigatórias, como parte do processo de organização dos Estados-nação, com destaque para a história da educação brasileira, século XIX e início do século XX. Para isso, foram investigados documentos como: relatórios de governo, jornais e revistas, discutidos à luz das teorias sociológicas de Norbert Elias e Anibal Quijano. Esses autores analisam, com ênfases diferenciadas, as dinâmicas monopolizadoras produtoras da modernidade europeia impostas nas Américas, as mudanças nas relações entre governantes e governados, e as tensões sociorraciais no processo de organização das nações. O estudo indica para paradoxos no processo de estabelecimento da escola pública obrigatória, uma vez que as ações voltadas para homogeneizar culturalmente as populações contribuíram para o surgimento de novos mecanismos de exclusão sociorracial.

Palavras-chave: Monopolização estatal; Escola obrigatória; Nação; Exclusão; Classe SOCIAL; ETNIA.

${ }^{\text {I }}$ Universidade Federal de Minas Gerais, Belo Horizonte, MG, Brasil 
Abstract The purpose of this article is to discuss the monopolization of education by the state and the imposition of cultural homogeneity through the institutionalization of public and compulsory schools, as part of the process of nation state organization, highlighting the history of Brazilian education in the nineteenth century and beginning of the 20th century. For this, documents such as: government reports, newspapers and magazines were discussed, in the light of the sociological theories of Norbert Elias and Anibal Quijano. These authors analyze, with differentiated emphases, the monopolizing dynamics of European modernity that have imposed themselves in the Americas, the changes in relations between governors and governed, and the socio-racial tensions in the process of the organization of nations. The study points to paradoxes in the process of establishing a compulsory public school, since actions aimed at culturally homogenizing populations have contributed to the emergence of new mechanisms of socio-racial exclusion.

Keywords: State monopolization; Compulsory school; Nation; Exclusion; Social class; EтHNICITY.

Resumen El objetivo de este artículo es discutir la monopolización de la educación estatal y la imposición de homogeneidad cultural a través de la institucionalización de las escuelas públicas y obligatorias, como parte del proceso de organización del Estado-nación, destacando la historia de la educación brasileña en el siglo XIX e inicio del siglo XX. Para ello, se discutieron documentos como: informes gubernamentales, periódicos y revistas, a la luz de las teorías sociológicas de Norbert Elias y Anibal Quijano. Estos autores analizan, con énfasis diferenciado, la dinámica monopolizante de la modernidad europea que se impusieron en las Américas, los cambios en las relaciones entre gobernadores y gobernados y las tensiones socio-raciales en el proceso de organización de las naciones. El estudio apunta a paradojas en el proceso de establecimiento de una escuela pública obligatoria, ya que las acciones destinadas a poblaciones culturalmente homogeneizadoras contribuyeron al surgimiento de nuevos mecanismos de exclusión socio-racial.

Palabras claves: Monopolización estatal; Escuela obligatoria; Nación; Exclusión; Clase social; Etnia.

\footnotetext{
Não há melhor povo para se governar do que aquele que for regularmente instruído: é essa uma verdade que mais de uma nação tem adotado como axioma; quanto mais instruído é um povo, tanto mais elemento de ordem existe entre ele, mais dócil se torna, e a convicção é o instrumento mais forte para se fazer as massas entrarem na órbita da moral e dos bons costumes. Essa instrução se obtém por meio de escolas regularmente distribuídas por todas as partes, e públicas, para que possa qualquer desfavorecido de meios usar delas (ALBUM LITTERARIO, 1861, p. 2; grifos da autora).
}

A citação, do período imperial, trata de uma assertiva compartilhada pelas elites de várias partes do mundo desde fins do século XVIII, isto é, a de que o povo precisava ser instruído, e que tal instrução deveria ser feita em escolas estatais, no propósito de tornar a 
população ordeira e governável. Essas formulações tiveram origem no contexto europeu das mudanças sociopolíticas em curso nos séculos XVIII e XIX, quais sejam, crise das monarquias absolutistas e organização das nações constitucionais; avanço das relações capitalistas de trabalho e industrialização; percepção de que não é possível governar sem levar em conta os governantes; debates relativos à necessidade de homogeneização cultural dos governados. Devido às dinâmicas colonialistas da época, tais acontecimentos repercutiram nas sociedades de outros continentes, com o estabelecimento simultâneo da escola estatal.

Contudo, apesar da consolidação das nações e da escolarização pública obrigatória, esse processo não se fez sem tensões e revelou paradoxos, ainda que com manifestações diferenciadas a cada país. Especificamente no Brasil, as iniciativas de popularização da escola, ao longo do século XIX, foram caracterizadas por precariedade de toda ordem, sendo que no início do século XX, ampliaram-se as desigualdades escolares, o que, ao contrário do que fora propalado pelas elites, contribuiu para aprofundar as desigualdades sociorraciais. ${ }^{1}$

Diferentes questões apresentam-se para o debate histórico e conceitual desse problema, e neste texto pretende-se discutir algumas delas. Para isso, foi realizado, sob aspecto metodológico, pesquisa histórica documental, mais especificamente, relatório de governo e análise de periódicos; estudo de clássicos da política e educação, centralmente Condorcet (1743-1794) e Ernest Renan (1823-1892), e diálogos conceituais com Norbert Elias (1993, 1994, 1997) e Anibal Quijano (2005, 2014). Observa-se que, embora Elias e Quijano possuam filiações teóricas distintas, eles convergem na problematização de temas fundamentais em discussão neste texto, quais sejam: interdependência e relações de poder; relação estabelecida e outsiders; estudos da subalternidade, e produção de estigmatizações como estratégia de elaboração da inferioridade do outro.

No conjunto da argumentação dos autores, aqui estudados, de modo geral, em que pese as diferenças teóricas e contextuais, nos deparamos com a problematização da demanda por civilização e educação, associada aos processos de organização das nações e estabelecimento dos parâmetros definidores do ser cidadão. Acrescento que, neste contexto, para dotar as nações de um "povo regularmente instruído", instituiu-se a monopolização dos saberes pelo Estado-nação, por meio do controle dos saberes escolares e da formação de professores, aspectos tidos como alicerces da homogeneização cultural. Como dissemos, a experiência europeia de monopolização estatal da escola primária infundiu-se nos diferentes continentes, ${ }^{2}$ portanto, não teve somente características locais ou nacionalistas, mas atingiu uma escala global.

A proposição europeia/ocidental de uma escola nacional foi globalizada desde o século XIX, integrando o processo de expansão do capitalismo industrial e liberalismo. No novo quadro político-econômico, a necessidade da "regular instrução do povo" fez-

1 Em relação à precariedade da escola pública brasileira, vários historiadores atestam esse fato, entre eles, VIDAL, SÁ e SILVA (2013); GONDRA e SCHNEIDER (2011); VEIGA (2007).

2 No caso brasileiro, o processo escolarizador foi instituído em meio à existência de relações escravagistas até 1888. 
-se fundamental no âmbito da interdependência entre as nações. Por sua vez, o padrão eurocêntrico de escola pública obrigatória disseminou a perspectiva cognitiva que lhe foi característica, fundada em conhecidos dualismos: racional-irracional; primitivo-civilizado; inferior-superior; razão-corpo; sujeito-objeto etc. Desse modo, para a "nacionalização do eurocentrismo", a heterogeneidade populacional de cada nação foi submetida a um processo interno de homogeneização cultural.

Se no âmbito global, o contraste das diferenças nacionais tornou-se um elemento fundamental para a instituição das novas relações internacionais de trabalho, e, portanto, manutenção de um equilíbrio de poder desigual, internamente, o processo de organização das nações demandou coesão e apagamento das diferenças. No Brasil, como observaremos, a implantação da escola pública fez-se em meio a muitas tensões sociais e opressão étnico-racial, ao longo do período imperial e primeiras décadas republicanas, a frequência e permanência do "povo" à escola foi rarefeita, a homogeneização cultural fez-se legitimada pela exclusão.

Para a discussão dessas questões, este texto está organizado em dois itens: formação das nações, escola nacional e monopolização da escola pelo Estado; homogeneidade cultural e exclusão sociorracial.

\section{NaÇão, ESCOLA NACIONAL E MONOPOLIZAÇÃo doS SABERES ELEMENTARES PELO ESTADO}

A riqueza e a civilização de um povo não se afere tanto pelo grau de desenvolvimento das ciências abstratas, como pelos costumes, educação moral e profissional de um povo. Sem obreiros inteligentes, hábeis, moralizados e que compreendam o valor do dever, da honra e dos bons costumes, nem uma forma de governo pode prosperar, nenhuma nação florescer (Relatório, 1873, Anexo, p. 6; grifos da autora).

Com base nesse argumento, o presidente da província de Minas Gerais defendia a importância da expansão da educação escolar. Contudo, tal afirmativa poderia ser de autoria de qualquer político, independentemente de sua origem, pois integra o movimento geral de organização dos Estados-nação, em fins do século XVIII e XIX, e representa a demanda por mudança de hábitos e costumes do povo, no contexto de fim do governo das monarquias absolutistas.

O sociólogo Norbert Elias (1997) problematiza os valores envolvidos na passagem dos Estados monárquicos para os Estados nacionais, quando as classes burguesas começaram a defender direitos humanos e o progresso natural da humanidade, como argumento para a eliminação da opressão absolutista. Nessa época, se a aristocracia depositava na ancestralidade familiar o orgulho de seu poder, a burguesia passou a defender a ideia de nação, fundada na tradição e cultura local de seus habitantes, como elementos identificadores de uma autoimagem positiva e da origem de governo. Transformada em valor público, a 
nação, como novo modo de organizar as populações, fez-se portadora dos ideais de civilização, progresso, enfim, da melhoria da condição humana.

\begin{abstract}
Entretanto, como demonstra Elias (1987), esses ideais foram alterados quando as classes burguesas ascenderam ao poder e se estabeleceram como novo grupo dominante. No contexto de consolidação da divisão de trabalho industrial-capitalista, os conceitos de civilização e cultura se estabeleceram como estados estáticos; por sua vez, a noção de cultura nacional se sobrepôs a questões humanistas e morais, e os direitos humanos, então proclamados, foram subordinados ao sentido abstrato de progresso e de deveres para com a nação. Fez-se necessário elaborar o sentimento de pertença nacional e do nacionalismo, em prol do progresso das nações, de modo a relativizar os direitos humanos universais, tendo sido produzido, inclusive, um léxico específico com qualidades emocionais para expressar as coletividades nacionais, tais como americano, brasileiro, inglês etc., e ainda, pátria, mãe- pátria, povo etc. (ELIAS, 1997, p. 139).
\end{abstract}

Como demonstra o antropólogo Ernest Gellner (1983), o sentimento nacionalista foi fundamental para o engendramento das nações. Para esse autor, o nacionalismo consiste na imposição geral de uma cultura homogênea a toda população, estruturada por um grupamento de conhecimentos a serem adquiridos na escola, quais sejam: “(...) alfabetização, calculo, hábitos de trabalho e fundamentos sociais básicos, e familiarização com os fundamentos técnicos e sociais básicos"3 (p. 45). Nesse sentido, a escola tornou-se a principal portadora da concepção estática das noções de cultura e civilização, e, portanto, do controle sobre o entendimento de aperfeiçoamento e progresso da humanidade. Contudo, ressalto que, essa função primordial da escola, somente poderia ser realizada, ao tornar-se monopolizada pelo Estado.

Conforme Elias (1993), uma característica fundamental das sociedades modernas ocidentais é a existência de monopolizações. Apoiado em Max Weber (1864-1920), ele demonstrou como a combinação entre a concentração do uso da força física e da tributação da propriedade nas mãos de uma autoridade central esteve na gênese do Estado moderno. Elias reflete que, mesmo que outros monopólios venham a surgir posteriormente, esses dois se estabeleceram como decisivos na organização do Estado moderno, sendo que a sua decadência levaria a arruinar o próprio Estado e tudo que se ampara nele.

$\mathrm{O}$ autor demonstrou ainda que a monopolização da violência pelo Estado contribuiu efetivamente para interferir na dinâmica dos comportamentos humanos numa direção bastante específica - o processo civilizador. Dessa maneira, é possível identificar uma estreita relação entre o processo de organização do Estado (controle social) e o processo civilizador (autocontrole). A demanda pelo desenvolvimento do autocontrole das condutas, como um novo habitus, inicialmente restrito aos membros da sociedade da corte europeia, se expande a partir do século XVIII.

3 “(...) alfabetización, cálculo, hábitos de trabajo y fundamentos sociales básicos, y familiarización con los fundamentos técnicos y sociales básicos” (GELLNER, 1983, p. 45). 
No século XIX, as nações europeias autodenominaram-se civilizadas, e disseminaram o seu modelo de organização social como o único possível para o desenvolvimento e o progresso das nações. Expressões como sociedade civilizada e civilizar o povo foram unanimidade e recorrentes nos discursos das elites políticas e intelectuais. Nunca é demais lembrar que, nesse mesmo contexto, a burguesia civilizada europeia invadiu a África e parte da Ásia, colonizando os seus habitantes e explorando as suas riquezas, com meios de violência os mais variados, submetendo e desqualificando as suas formas de organização social. A ideia de instituir e disseminar padrões de moral e costumes civilizados, para todas as sociedades, globalizou-se, sendo que a monopolização estatal do ensino foi fator decisivo de organização dos Estados-nação e do processo civilizador em curso.

Debatida na Europa desde o início do século XVIII, a monopolização da escola elementar pelo Estado consolidou-se ao longo do século XIX, quando em diferentes nações, o Estado passou a regulamentar o processo de sua efetivação, instituindo currículo mínimo, material pedagógico e livros, tempo de escolaridade, formação de professores, autorização para abertura de escolas, certificação. A proposta de escolarização ampliada da população permitiu a homogeneização dos padrões da criança civilizada, por meio da imposição de modelos universalizados de aprendizagem e comportamento. Isso favoreceu a divulgação de novas identidades desqualificadoras e estigmatizadoras das crianças oriundas de baixos estratos sociais, ou mesmo para aquelas que não se adequaram, por diferentes motivos, aos novos modelos.

Para refletirmos sobre esse processo, há de se destacar que, durante largo tempo histórico, predominaram práticas difusas de aprendizagem, não havia uma estrutura monopolista encarregada de ordenar o conhecimento e a sua transmissão. Isso se modificou com a introdução do catolicismo no ocidente, quando a igreja passou a centralizar a educação, principalmente no período medieval, por meio das universidades. Ao longo da vigência do absolutismo e como consequência dos conflitos religiosos, a monopolização dos saberes pela igreja expandiu-se com a criação de colégios de diferentes ordens religiosas, embora, já nesse mesmo contexto, a fundação de universidades deixou de ser prerrogativa apenas do papado, mas também de príncipes. Também, ainda que a igreja controlasse grande parte dos aparatos de difusão do conhecimento, desenvolveram-se na modernidade sociedades científicas e literárias, gabinetes, laboratórios, museus e bibliotecas para fins de estudos e debates. Ainda assim, de maneira geral, entre o século XV e meados do XVIII, grande parte das populações europeias e colonizadas, não tinha acesso ao conhecimento produzido nesses espaços, bem como, à cultura escrita, nem mesmo frequentava escolas.

As primeiras iniciativas de monopolizar os saberes elementares pelo Estado se fizeram ainda pelos reis absolutistas, por exemplo, na Prússia e Portugal, seguido de outros Estados, com repercussão nas colônias. No caso brasileiro, as reformas pombalinas de 1759 instituíram as aulas régias e órgãos de regulação e administração do ensino. Algumas questões se colocam: quais foram as condições favorecedoras da formação do monopólio do ensino pelo Estado? Por que a igreja perdeu a hegemonia na centralização da educação dos jovens? Que lutas e disputas estiveram presentes? Por que e como o ensino tornou-se um monopólio público? 
A monopolização estatal do ensino é, evidentemente, decorrente da própria formação do Estado. A monopolização dos tributos foi precondição para o financiamento da escola e para a sua universalização. Por sua vez, a monopolização da violência engendrou profundas alterações nas condutas, mudou a relação com o conhecimento, produziu demandas de novos saberes. O acúmulo dessas experiências, associado à consolidação do Estado como forma monopolista de governo, foram fatores que produziram manifestações da necessidade de redimensionar a organização da educação sob a direção do Estado.

Conforme Elias (1993), a sociodinâmica da monopolização compreende duas fases a primeira, caracteriza-se pela competição, e por processos eliminatórios que resultam no monopólio restrito ou privado; a outra é a conversão de monopólios privados em monopólio público. A primeira fase pressupõe os seguintes fatores: livre competição entre unidades menores; desequilíbrio entre a demanda e a oferta do objeto do monopólio; crescente divisão de trabalho e interdependência entre os grupos sociais. A segunda, relaciona-se aos processos de administração e formas de controle do monopólio.

Especificamente no caso da educação, podemos dizer que, durante a vigência das monarquias absolutistas, a competitividade entre os espaços de produção e a circulação de saberes era muito diferenciada. $\mathrm{O}$ acesso erudito ao conhecimento de doutrinas religiosas foi exclusividade dos estudos superiores de teologia ou em seminários de padres. Já a doutrinação religiosa da população pobre, nos países católicos, foi disputada entre as várias ordens religiosas criadas no contexto, e se realizava pela pregação oral, sem a precondição da leitura. Nos países protestantes, ocorreu o inverso, a aprendizagem da leitura na língua materna foi condição fundamental de difusão da crença. Nas colônias europeias, investiu-se na catequização das populações locais, com destaque para a ação dos jesuítas na América Latina.

Já as universidades eram também, em geral, administradas pela igreja, católicas ou protestantes, embora funcionários do Estado estivessem à frente das instituições de origem monárquica. A oferta de cursos era pouca, com destaque para medicina e direito. Como demonstrou Christopher Hill (1992), as origens intelectuais da revolução industrial não estiveram nas universidades. Assim, sociedades científicas e outros espaços de produção de saber, criados nesse contexto, foram fundamentais para o progresso das ciências, por meio da realização de experimentos, conferências e, principalmente, publicações em impressos especializados.

Entre as instituições escolares, merece destaque a criação dos colégios, cuja centralização administrativa esteve sob o comando da igreja protestante ou de ordens religiosas católicas, com destaque para a rede de colégios jesuítas. A proeminência desses colégios foi a de se especializarem na educação de filhos de nobres e burgueses por meio da difusão do latim e da retórica, conhecimentos indispensáveis tanto para a vida social na corte, como para os estudos superiores de direito e/ou para exercerem cargos de administração no governo. Muitos colégios dispunham de currículo vasto, que incluía regras de civilidade, dança e esgrima. 
Quanto ao ensino dos saberes elementares, esses se faziam de modo disperso - em casa, com mestres particulares, nas escolas dominicais ou colégios. Interessa-nos aqui refletir que o domínio dos saberes elementares, por parte das camadas mais pobres da população, em geral, pelo menos até o século XVIII, não se apresentava como uma questão importante para a organização das sociedades. Havia poucas instituições especializadas na transmissão desses saberes, e quando existiam dedicavam-se, em geral, à doutrinação religiosa e/ou à assistência, como foi o caso das escolas protestantes dominicais ou as escolas lassalistas ${ }^{4}$ na França.

Contudo, no século XVIII, nos países católicos, a centralidade educacional na doutrina religiosa passou a ser criticada, em meio às novas demandas sociais e políticas. Houve ampla divulgação da necessidade, não somente de uma reforma política, mas de uma reforma social mediada pela escolarização, num momento de crescente laicização do ocidente. Entre burgueses e alguns setores da nobreza, a aquisição de novos conhecimentos começou a se apresentar como vetor de socialização e distinção social, o que pode ser percebido no convívio dos salões, sociedades literárias, gabinetes de leitura, laboratórios, viagens e expedições científicas. Também se ampliaram as formas materiais de circulação do conhecimento, como jornais, livros, panfletos. A partir da revolução industrial, o conhecimento das ciências consolida-se como fator de enriquecimento.

Dessa maneira, intensificaram-se também os debates que questionavam a hegemonia da igreja frente à educação, sob o argumento de que era necessário estender a civilização para o povo. Nos dizeres do filósofo Holbach, em obra de 1774, "A razão humana não é ainda suficientemente exercitada; a civilização dos povos não se completou ainda (...)". ${ }^{5}$ Nesse contexto produziu-se o entendimento da centralidade cognitiva no uso da razão, e, por conseguinte, da necessidade de civilizar o povo por meio da imposição da racionalidade iluminista, no objetivo de retirá-lo do estágio de "barbárie" e "ignorância". Embora tenha sido um movimento heterogêneo, o pensamento iluminista se unifica na afirmação do potencial racional dos indivíduos, na crença do seu aperfeiçoamento contínuo e aprimoramento do meio social. Essas proposições ampliaram-se no contexto de complexificação da divisão do trabalho industrial-capitalista, constituição de novas relações de interdependência entre as diversas classes sociais e organização dos Estados-nação.

Desde então, a defesa da institucionalização de uma escola elementar realizou-se, cada vez mais, como questão de interesse público, a ser monopolizada pelo Estado; e, com o fim do absolutismo, a difusão da escola apresentou-se como fator decisivo na organização dos Estados-nação constitucionais e para o controle da nova condição jurídica das populações. Se a monopolização dos saberes pela igreja foi importante para a disseminação da doutrina cristã, a monopolização estatal propiciou a disseminação dos valores racionalizados do ocidente autodenominado civilizado. Isso demandou uma homogeneização cultural fundada nos modelos de autocoerção, de domínio das emoções e sensos de vergonha e pudor, bem

\footnotetext{
4 Escolas gratuitas de orientação católica criadas por Jean Baptista de La Salle (1651-1719), fundador da congregação dos Irmãos Lassalistas.

5 Apud Elias (1994, p. 61).
} 
como, na imposição da cultura escrita, dos saberes científicos e ideais de nação e pátria, em contraste aos hábitos e costumes tradicionais de diversos grupos sociais.

Ernest Renan, no clássico "Que é uma nação”, de 1882, afirmava que, embora as consequências "sejam benéficas", nenhuma nação se organiza sem violência, sem extermínio de pessoas, sem aniquilar crenças e culturas, e isto se faz pela imposição do esquecimento de certo passado. E afirma: "O esquecimento, e mesmo erro histórico, são um fator essencial na criação de uma nação...Ora, a essência de uma nação está em que todos os indivíduos tenham muito em comum, e também que todos tenham esquecido muitas coisas" (RENAN, 1997, p. 161-162). A escola, em suas origens, apresentou-se como lugar do esquecimento das tradições dos povos submetidos e da invenção de outra memória.

\title{
HOMOGENEIDADE CULTURAL E EXCLUSÃO SOCIORRACIAL
}

\begin{abstract}
É isso que esperamos que o Congresso aqui reunido indique aos governos porque, cooperando para isso nós vamos cooperar para a formação efetiva e real da nacionalidade brasileira. Povo, todos nós sabemos, não é um amontoado de homens, não é uma aglomeração de pessoas limitadas por tal e tal serra e por tal rio. Povo é uma comunhão de seres com os mesmos interesses, batalhando pelos mesmos ideais, relembrando, no presente, os mesmos fatos históricos, e principalmente falando a mesma língua (...) nós, que temos um povo assim por circunstâncias especiais de colonização e de geografia tão diverso, tendo uma história ainda pouco definida, precisamos dar a esse povo o forte elo da língua, precisamos fazer com que todo ele, educando-se, aprendendo a ler, aprenda a conhecer a história nacional, aprenda a história de nossos vultos principais, quer sejam eles vultos de guerreiros, quer sejam vultos de homens de ciência ou de lutadores que se têm vindo batendo, desde tempos imemoriais de nossa Pátria, em benefício de nobres ideais (ANNAES, 1912, p. 166; grifos da autora).
\end{abstract}

Esse trecho é parte do discurso de Everardo Backheuser, por época do II Congresso Brasileiro de Instrução Primária e Secundária, realizado em Belo Horizonte, de 28/09 a 04/10/1912. Como o autor acentua, é preciso inventar outra história, de modo a unificar o povo, pois não se faz uma nação sem homogeneidade cultural. Da mesma forma, o professor Cypriano de Carvalho, diretor da Escola Normal da Capital, presente no mesmo evento, reforçava também a necessidade de produção de "opiniões e hábitos uniformes" e de uma doutrina nacional comum (ANNAES, 1912, p. 142). Igualmente, o professor José Botelho Reis argumentava quanto à fundamental importância da escola pública como condição de coesão social.

Se, no regime democrático, há necessidade de que cada cidadão, para a conservação da ordem social, conheça bem os seus direitos e deveres; se a instrução destrói os males da ignorância, diminuindo os vícios e os crimes; se a instrução aumenta a fortuna e o poder das nações, ao Estado, principalmente, compete proporcionar e facilitar os meios de instruir os seus filhos, tornado a educação ao alcance de todas as classes, pela criação de escolas e pela gratuidade do ensino básico - o primário (ANNAES, 1912, p. 238; grifos da autora). 
Passados mais de dez anos, o médico e político Miguel Couto, numa conferência proferida nos idos de 1927, intitulada "No Brasil só há um problema nacional: a educação do povo", alertava: "É forçoso criar fortes correntes internas de sentimentos e de ideias, que liguem os nossos destinos, e a base de tudo isto é a escola primaria (...) Que nos resta fazer se nós queremos nos conservar como uma racionalidade única?" (COUTO, 1927, p. 15; grifos da autora).

Essas citações suscitam importantes questões para a discussão da institucionalização da escola pública brasileira. Estabelecida pela Constituição de 1824, no período imperial, a escola foi declarada pública e gratuita, e, posteriormente, de acordo com cada província, também obrigatória; desde então, foi anunciada como instituição essencial para a difusão da moral e dos costumes necessários para a organização da nação brasileira. Contudo, nesse período, as políticas educacionais eram extremamente precárias, uma vez que não foram criadas condições efetivas para todas as crianças frequentarem a escola, por diferentes fatores, tais como, pobreza da população, trabalho infantil, falta de escolas, de materiais e professores adequadamente preparados (GONDRA e SCHNEIDER, 2011; VEIGA, 2007). ${ }^{6}$ A principal comprovação disso está no analfabetismo constatado em fins do século XIX, quando o Brasil apresentava um índice em torno de 85\% (VEIGA, 2007).

Assim, devido ao fracasso das políticas imperiais e o alto índice de analfabetismo, os apelos de políticos e intelectuais, nas primeiras décadas republicanas, para a expansão da escola pública, foram bem mais incisivos, sem contar que estava em vigência, desde 1881, a lei que exigia a qualificação de ser alfabetizado para votar. O enfoque na homogeneização cultural e na difusão de uma "racionalidade única", por meio da escola primária, foi assunto recorrente nos debates políticos da época. Ainda assim, as reformas educacionais instituídas continuaram não favorecendo o acesso e a permanência dos filhos do povo na escola, isso devido à continuidade de problemas como a pobreza da população e o trabalho infantil, mas também, a introdução de uma oferta escolar muito desigual. Neste item, serão discutidas estas questões. De que modo a imposição de homogeneidade cultural favoreceu a exclusão sociorracial?

A institucionalização de uma escola pública e obrigatória para toda população, como parte de organização das nações, originalmente propalou-se na Europa como fator de controle das igualdades jurídicas. A Constituição francesa de 1791 estabelecia que "Será criada e organizada uma instrução pública, comum a todos os cidadãos, gratuita no que diz respeito aos conhecimentos necessários para todos os homens (...)" (apud CONDORCET, 1943, p. VI). Os saberes elementares definiram-se de acordo com o que se julgou necessário para homogeneizar culturalmente os diferentes grupos sociais e estabelecer a "racionalidade única". De acordo com o constituinte francês Condorcet,

Ensinar-se-á nestas escolas a ler e a escrever, o que implica necessariamente algumas noções gramaticais. Agregar-se-ão a este estudo as regras da aritmética

6 Também a situação de precariedade da instrução no império pode ser conferida nos dados trazidos por Almeida (1989), em tese de 1889. 
e os métodos simples para medir um terreno e um edifício; uma descrição elementar dos produtos do país e dos rudimentos da agricultura e das artes [ofícios mecânicos]; o desenvolvimento das primeiras ideias morais e das regras de conduta que delas derivam; finalmente, os princípios de ordem social que possam colocar-se ao alcance da inteligência infantil (CONDORCET, 1943, p. 12).

O político recomendou, ainda, a organização de festas cívicas nacionais nas escolas, o enaltecimento da memória dos homens cujas virtudes honraram a vida da nação; o ensino dos deveres dos cidadãos para com sua pátria (CONDORCET, 1943, p. 15), ensinamentos esses somente possíveis pelo silenciamento ou apagamento de outras memórias. Observa-se, porém, que, desde os debates iniciais, a proposição de uma instrução geral não significou igual para todos, evidenciado tanto pela definição diferenciada da duração do tempo escolar, como pela adoção do sistema da meritocracia.

Para os políticos da época, uma difícil questão se colocava: em sendo as condições de vida dos homens muito desiguais, como definir o que é necessário para todos? Condorcet, já naquela época, teve que admitir, e afirmou: "É impossível submeter, a uma educação rigorosamente igual, homens cuja destinação é tão diferente" (CONDORCET, 2008, p. 43). Esse político inaugurou a lógica escolar linear atual, e junto a ela uma nova hierarquia social, fundada na hierarquia da escolarização. Por exemplo, sobre a duração de quatro anos da escola primária, justificava que, esse tempo,

(...) corresponde também, com bastante exatidão, ao espaço de tempo que, para as crianças de famílias mais pobres, transcorre entre a época em que começam a ser capazes de aprender e aquela em que podem ser empregadas num trabalho útil, submetidas a uma aprendizagem regular (CONDORCET, 1943, p. 12).

Segundo Condorcet (2008), era preciso estabelecer diferentes percursos de instrução, não somente devido à condição social do aluno, mas também, de acordo com o mérito, ou seja, sua dedicação, talento e "facilidade para aprender" (p. 35). Como sabemos, no século seguinte, os estudos científicos da biologia e psicologia se dedicaram a produzir instrumentos para medir talentos, favorecendo a divulgação de uma moral política, ao atribuir as crianças "malsucedidas" na escola identidades como atrasadas, preguiçosas e indolentes.

De acordo com Elias (1993), a meritocracia foi uma invenção típica da sociedade industrial burguesa, que substituiu o poder advindo do privilégio de nascimento pelo poder conquistado por mérito individual. Nesse contexto, ganharam destaque estudos sobre habilidades e aptidões intelectuais, inatas e/ou adquiridas, e a função da escola como promovedora de oportunidades de ascensão social, regulando assim a igualdade jurídica. Elias observa que, no século XIX, com a gradual ascendência dos diferentes estratos burgueses e as alterações nas relações de poderes, novas aptidões se fizeram necessárias e decisivas para,

(...) o sucesso ou o fracasso nas lutas por status e poder (...) aptidões como a proficiência ocupacional, perícia na luta competitiva por oportunidades econômicas, na aquisição ou controle da riqueza sob a forma de capital, ou as finali- 
dades altamente especializadas necessárias para o progresso político nas lutas partidárias ferozes, embora reguladas, que caracterizam uma era de crescente democratização funcional (ELIAS, 1993, p. 252-3).

A aplicação dos princípios da meritocracia na organização da escola pública obrigatória consolidou conhecidas dicotomias, como medíocre-inteligente, racional-irracional, primitivo-civilizado. Com isso, produziu o entendimento do analfabeto como ignorante e da ignorância como problema, desqualificando e estigmatizando os pobres, camponeses, trabalhadores, mulheres, negros, mestiços. Nas palavras de Condorcet,

Enquanto deixardes uma grande parte da população presa na ignorância e, portanto, à mercê da sedução, dos preconceitos e das superstições, não realizareis o objetivo que vos deve propor: o de mostrar, enfim, ao mundo, uma nação em que a liberdade e a igualdade sejam para todos um bem geral de que sabem gozar e cujo preço conhecem (...) a igualdade de instrução deve diminuir as outras desigualdades naturais (CONDORCET, 2008, p. 99; grifos da autora).

Não obstante, paradoxalmente, desde a difusão e implementação institucional da "igualdade de instrução", aprofundaram-se os mecanismos produtores de desigualdades sociorraciais. A propagação da necessidade de institucionalização da escola primária, como fator de coesão social e diminuição das desigualdades, pela imposição da palavra escrita, da leitura e história nacional, fez-se no mesmo contexto enciclopedista de divisão da humanidade em povos com história e povos sem história, cuja referência foi o padrão europeu do registro escrito.

Desse modo, infundiu-se, inclusive, uma cultura historiográfica estruturada na divisão pré-história e história, constituidora do entendimento linear e evolucionista do tempo individual e social, no eurocentrismo e na invenção do ocidente como portador da modernidade e do progresso (SAID, 2007). Entretanto, a consolidação dessas concepções somente foi possível pela estigmatização dos povos sem a escrita de padrão europeu como inferiores e subalternos. Nas palavras de Miguel Couto, o "Brasil espera que cada um cumpra o seu dever", caso contrário, (...) "na ignorância se afundam cada vez mais para a subalternidade e a degenerescência" (COUTO, 1927, p. 9).

Assim, na América Latina, a imposição da escola pública e obrigatória foi a culminação de um processo de subalternização de vários grupos sociais, iniciado com a colonização moderna. Como bem demonstra Anibal Quijano (2005, 2014), desde o século XVI inaugurou-se um novo padrão mundial de poder fundado em dois eixos fundamentais: a classificação das populações pela categoria mental raça, e a instauração de uma divisão racial do trabalho, legitimadora das relações de dominação. Esse foi o contexto da colonização, submissão e escravização dos povos habitantes das terras invadidas por espanhóis, portugueses e ingleses, escravização dos povos africanos, e estabelecimento de relações étnico-raciais hierarquizadas, legitimadoras da inferiorização dos povos colonizados, por meio da desqualificação e estigmatização de sua estética, sua cultura, seus processos de elaboração de conhecimento e sensibilidades. A escola primária apresentou-se como ins- 
tituição regeneradora da raça, cujos discursos abusavam de adjetivos desqualificadores. De acordo com artigo da Revista Escolar, era fundamental convencer as populações a frequentá-la,

(...) despertem as diversas classes de sua indiferença pela instrução popular, e do povo mineiro, composto em sua maioria, de ignorantes, rotineiros, pobres e libertos, surgirá uma geração nova, iluminada, ativa e empreendedora, a quem a nossa opulenta natureza franqueará todos dos seus tesouros e todas as suas riquezas (Revista Escolar, ano 1, n. 5, 23/03/1889, p. 2; grifos da autora).

Norbert Elias (2000), ao apresentar o modelo teórico figuração estabelecidos-outsiders como instrumento de análise das relações de desequilíbrio de poder entre pessoas/ grupos sociais, demonstra a importância da estigmatização nas disputas de poder, como estratégia de manter a superioridade de um grupo sobre o outro. Acrescento que o processo escolarizador contribuiu efetivamente para a invenção de identidades e qualificações de inferiorização da população outsider, ou para a subalternização dos filhos do povo, na perspectiva de Quijano (2005), adensando os conflitos sociorraciais constituidores do processo de organização da nação brasileira.

Na história da educação do Brasil, a imposição da escola obrigatória e o estabelecimento da homogeneidade cultural ampliaram a visibilidade das diferenças étnico-sociais e preconceito racial, dificultando ainda mais a mobilidade social. Desde o império, a principal característica da cultura escolar brasileira foi o questionamento das condições de educabilidade da população, uma questão inventada, sem precedência, pois a escola era totalmente precária, sendo, em geral, frequentada por crianças pobres, negras e mestiças, de modo bastante irregular, devido ao trabalho, necessário para o auxílio às suas famílias (VEIGA, 2007, 2016a). De acordo com Quijano (2014), a inferiorização das populações pela hierarquia racial mostrou-se mais duradoura e estável que o próprio colonialismo, processo nomeado por ele como "colonialidade do poder"?

A perspectiva de criação das nações e o aniquilamento do modo de vida de inúmeros grupos sociais acirraram os processos de exclusão. A afirmativa do professor José de Araújo Lima, no evento de Belo Horizonte, confirma, “(...) De facto, à medida que os antropologistas e sociólogos modernos aprofundam a análise dos problemas sociais e étnicos, se aproxima cada vez mais, decididamente, dessa verdade, segundo a qual a noção de raça se deve opor a noção de povo, a noção de nacionalidade" (ANNAES, 1912, p. 169).

Com a República, os instrumentos de inferiorização de pobres, mestiços e negros agravaram-se. Organizada a República como federação, os anos iniciais caracterizaram-se por elaboração das reformas estaduais e ausência de um plano nacional de educação, ainda

\footnotetext{
7 Assim afirma, "A colonialidade é um dos elementos constitutivos e específicos do padrão mundial do poder capitalista. Sustenta-se na imposição de uma classificação racial/étnica da população do mundo como pedra angular do referido padrão de poder e opera em cada um dos planos, meios e dimensões, materiais e subjetivos, da existência social cotidiana e da escala social. Origina-se e materializa-se a partir da América" (QUIJANO, 2014, p. 285).
} 
que tenha ocorrido movimentação de educadores e políticos para esse fim. ${ }^{8}$ Mas, apesar de estadualizados, os modelos escolares implantados nos Estados foram semelhantes, caracterizando uma oferta muito desigual de escola: grupos escolares, escolas isoladas, escolas rurais, escolas em abrigos, escolas-reformatórios para "delinquentes e pervertidos" (previsto no Código de Menores de 1927).

Além da desigualdade escolar, o país aprofundava as desigualdades sociorraciais, com o crescimento da exploração do trabalho de crianças pobres, negras e mestiças, bem como, com os debates relativos à regulamentação do trabalho infantil e escolarização (VEIGA, 2016b). Tal como na França do século XVIII, constatou-se que não era possível uma escola igual para crianças com destinos tão diferentes.

$\mathrm{Na}$ explicação do Secretário do Interior de Minas Gerais, “(...) $\mathrm{Na}$ escola isolada, todas as classes são regidas pelo mesmo professor, ao passo que no grupo, cada professor tem a sua classe, fazendo-se assim, o ensino simultâneo, que é sem dúvida, mais proveitoso" (ANNAES, 1912, p. 234). Por sua vez, os grupos escolares favoreceram a elitização da escola primária, devido à implantação de novos mecanismos de apuração do rendimento escolar, seleção de alunos, implantação de testes escolares. Essas práticas contribuíram para a exposição negativa das crianças que não conseguiram atender ao padrão da escola básica em vigência, em geral crianças pobres, negras, mestiças, da roça (VEIGA, 2017).

Num plano mais específico, o desenvolvimento dos conhecimentos científicos sobre a criança produziu uma profunda repercussão na organização escolar e nos procedimentos pedagógicos. A abertura da escola primária para amplas camadas da população, envolvendo gêneros, etnias e classes sociais diferenciadas, foi um acontecimento necessário para regular os processos de inserção social, no objetivo de resolver a difícil questão da "igualdade de todos perante a lei”. A difusão da escola criou uma nova condição de infância civilizada, a criança escolarizada, mas também diferenciada pela própria escola. Contribuiu para isso a organização racional das classes homogêneas, possibilitada pela aplicação dos testes psicológicos e aferição das diferenças da inteligência. É nesse aspecto que se alteraram os procedimentos identitários das crianças, sendo possível classificá-las a partir de categorias formuladas cientificamente. Vários foram os estudos que associaram as idades cronológicas das crianças à idade escolar e idade mental, a partir de diferentes obras de especialistas de fins do século XIX. Firmados na cientificidade, os especialistas confiavam largamente na intervenção calculada e quantificada na escola.

A classificação de uma criança foi objeto de estudo de diferentes autores e gerou variada nomenclatura, podendo ser identificada, por exemplo, como, normal, anormal, regular, irregular ou, média, inframédia, supermédia ou, ainda, conforme, desconforme, forte ou fraca (LOURENÇO FILHO, 1974). Como exemplo de nomenclaturas, Alfred Binet ${ }^{9}$ (1857-1911) classificou as "crianças anormais" como idiotas, imbecis e débeis mentais,

8 Entre as ações destacam-se o II Congresso da Instrução Primária e Secundária, realizado em 1911, Belo Horizonte; a criação da Liga Brasileira contra o Analfabetismo, 1915; Conferência Interestadual de Ensino Primário, realizada em 1922, Rio de Janeiro; criação da Associação Brasileira de Educação (ABE), 1924; realização das conferências nacionais de educação promovidas pela $\mathrm{ABE}$.

9 Apud Lourenço Filho. Introdução ao estudo da Escola Nova. São Paulo: Melhoramentos, 1974. 
sendo que o imbecil foi categorizado como a criança que não chega a ler e escrever depois de dois anos de escolaridade. Além disso, as crianças foram classificadas também de acordo com suas condições de saúde mental e emocional, ampliando-se o rol de categorias identificadoras, como, equilibrada, desequilibrada, imatura, madura, portadora de deficiências sensoriais e motoras, além das codificações do grau de (des) ajustamento social: tímida, assustada, medrosa, irritada (LOURENÇO FILHO, 1974).

Dessas várias categorias originou-se uma definição que viria marcar o curso da vida de muitas crianças, o de criança-problema. Na denominação de Lourenço Filho (1974), criança-problema é aquela com dificuldades de ajustamento no meio familiar e na escola, por extensão na sociedade. Por um longo período histórico, essa foi a maneira como as crianças foram "repartidas" nas diferentes classes escolares, de acordo com a idade mental e do estado emocional auferidos em testes. A contrapartida do estabelecimento da homogeneidade cultural foi a elaboração de um processo científico de regulação da inclusão/ exclusão sociorracial.

\title{
CONSIDERAÇÕES FINAIS
}

No jornal A República, de 28/07/1902, publicava-se:

\begin{abstract}
Instrução, educação e trabalho, a trindade indispensável a uma nacionalidade que deseja ser forte, respeitada, próspera e civilizada. O povo que não possui isto é fraco, pobre e atrasado. Múltiplas são as causas do nosso definhamento. Em primeiro lugar a nossa origem (...) Amalgama ou mescla de sangue português, africano e indígena, eis a formação plástica, moral e intelectual do nacional, isto é, retrogradação, incipiencia, astucia, indolência, superstição, etc. (...) Como pois, preparar uma nacionalidade forte, viril, instruída, tendo a compreensão nítida de seus elevados destinos, dos seus direitos cívicos, se desde a sua infância lhe foi inoculado o vírus corrosivo do banditismo da raça preta, que significa servilismo, indolência e perversão moral? (...) (A República, 28/07/1902, p. 1; grifos da autora).
\end{abstract}

O que esperar de uma nação, cujas elites organizadoras, estigmatizavam, inferiorizavam e criminalizavam os povos convocados a formá-la, devido às suas origens sociorraciais? O que esperar de uma escola que se propunha propagadora de uma racionalidade única, e, portanto, desqualificadora das tradições históricas de seus sujeitos? Essas questões podem ser pensadas como questões universais, pois a associação entre a formação das nações constitucionais e a implementação/popularização da escola pública primária obrigatória, de origem europeia/ocidental, difundiu-se por diferentes partes do mundo.

O desenvolvimento das relações de trabalho capitalista, combinado com o estabelecimento das igualdades jurídicas, se fizeram concomitantemente à necessidade de uma nova organização política e outra administração da produção e difusão do conhecimento. Essas mudanças históricas tiveram uma característica essencialmente globalizada, tendo em vista o tipo de interdependência que se estabeleceu entre as diferentes nações. Por sua vez, as 
críticas aos governos absolutistas ensejaram também os debates e os movimentos pelos direitos humanos e direitos civis, em profusão desde fins do século XVIII, em combate às desigualdades de toda ordem, colocando em evidência discursos humanitários e universalistas. Mas, paradoxalmente, como analisa Lynn Hunt (2009), "a própria noção de direitos humanos abriu inadvertidamente a porta para formas mais virulentas de sexíssimo, racismo e antissemitismo" (p. 188). A difusão da escola pública integra esse contexto de paradoxos, pois, foi instrumento de luta pela democratização do acesso ao conhecimento, do mesmo modo que instituiu novos processos sociais de exclusão.

As prerrogativas produzidas para a organização e o progresso das nações, como "educação, instrução e trabalho", não seriam efetivadas sem a monopolização dos saberes elementares pelo Estado. A contribuição de Norbert Elias (1993) para essa discussão é fundamental, o modelo teórico da sociodinâmica das monopolizações favorece a reflexão sobre o significado histórico de concentração dos processos educativos em uma autoridade central, no caso o Estado; seu diferencial em relação à igreja, e os mecanismos de formação dessa monopolização. Na verdade, a extensão da escolarização a todos promoveu o monopólio estatal de inserção controlada de todos na sociedade, fundado na concepção de meritocracia, instituído por meio do estabelecimento de um currículo único e hierarquizado; da duração variada do tempo escolar; de processos seletivos internos à escola.

Do mesmo modo que a organização das nações intensificou os processos de desestruturação social dos povos convocados a formá-la, usando de violência e/ou extermínio, além de produzir identidades estranhas às suas origens e tradições, também a escola teve um papel decisivo nesse processo. De modo geral, a escola se impôs pela violência pedagógica, fazendo largo uso das práticas de castigos físicos e morais. Os processos seletivos internos, por sua vez, contribuíram para a produção de novas identidades das crianças, como aluno atrasado, rebelde, preguiçoso, falador etc. Também a obrigatoriedade escolar contribuiu para a desorganização familiar e o surgimento de tensões entre as famílias e o Estado, pois, criou situações extremamente conflituosas para as famílias pobres, que precisavam do trabalho dos seus filhos, e não podiam enviá-los à escola.

As ações do Estado no propósito de inclusão dos pobres e trabalhadores à escola pressupõem homogeneização das relações sociais, que, por sua vez, somente se estabeleceram como homogêneas por meio de práticas regulamentadoras e controladoras das diferenças. Isso implicou na homogeneização das relações de gênero, constituída na afirmação da inferioridade feminina; de etnia, pela inferiorização dos negros e mestiços; e de classe social, pela estigmatização dos pobres. A difusão da igualdade jurídica deu maior visibilidade não somente às diferenças humanas, mas também às condições de desigualdade dos diferentes grupos sociais, desse modo é que as ciências, do século XIX pretenderam promover, principalmente, por meio da biologia e psicologia, uma naturalização das desigualdades sociorraciais, estabelecendo classificações e hierarquizações das condições individuais dos humanos quanto ao gênero e origem étnico-racial, além do investimento na classificação de capacidades/méritos intelectuais, caráter, moral etc. 
Para a ampliação do entendimento desse contexto, temos que, na perspectiva de Anibal Quijano, os processos colonizadores encetados nos primórdios da modernidade foram além da própria colonização, pois a colonialidade do poder consolidou a hierarquia racial e a divisão internacional e racial do trabalho, como padrão mundial de dominação. Compreendo a imposição da escola pública obrigatória como parte desse processo, seja por seleções internas ou externas, sua legitimidade fez-se pela naturalização das oportunidades de ascensão social pelo mérito. No caso específico das relações étnico-raciais, a hierarquia racial esteve presente na literatura, nas festas escolares, nas imagens veiculadas em livros e cartazes escolares, mas também nos gestos cotidianos de constrangimento pela cor, produzindo-se uma "escola de alma branca" (VEIGA, 2000). A escolarização da cor previu o "branqueamento" das crianças negras e mestiças, que porventura frequentaram a escola, por meio da interiorização de saberes, atitudes e valores da "raça civilizada". Por sua vez, uma seleção externa esteve em curso, visto que muitas crianças negras e mestiças não frequentaram a escola devido à exploração de seu trabalho.

Portanto, a propagação da escola básica, pública e universal, gratuita, obrigatória, não cumpriu a sua função de reguladora da igualdade, tal qual almejada por Condorcet e muitos outros. Ao contrário, reforçou os preconceitos, e criou um novo - o de ser uma pessoa não escolarizada, analfabeta ou imbecil, por não aprender a ler; além do mais, a exigência social de ser escolarizado e a imposição da homogeneidade cultural, ampliou o leque de motivos de exclusão social. Ao que tudo indica, no âmbito das sociedades de mercado capitalista, a escola dificilmente cumprirá a sua função de promovedora da igualdade de oportunidades, isso explica as desigualdades escolares como expressão das tensões nas sociedades de direitos.

\section{REFERÊNCIAS}

ALMEIDA, José Ricardo Pires de. História da instrução pública no Brasil, 1500 a 1889. São Paulo: Educ; Brasília: Inep/MEC, 1989.

CONDORCET, Jean-Antoine-Nicolas de Caritat. Cinco memórias sobre a instrução pública. São Paulo: UNESP, 2008. nal, 1943.

. Instrução Pública e Organização do Ensino. Porto: Livraria Educação Nacio-

ELIAS, Norbert. O processo civilizador, volume 1: uma história dos costumes. Rio de Janeiro: Jorge Zahar Ed., 1994.

. O processo civilizador, volume 2: formação do estado e civilização. Rio de Janeiro: Jorge Zahar Ed., 1993.

. Os alemães. A luta pelo poder e a evolução do habitus nos séculos XIX e XX.

Rio de Janeiro: Jorge Zahar Ed., 1997. 
ELIAS, Norbert e SCOTSON, John L. Os estabelecidos e outsiders: sociologia das relações de poder a partir de uma pequena comunidade. Rio de Janeiro: Zahar, 2000.

GELLNER, Ernest. Naciones y nacionalismo. Buenos Aires / Madrid: Alianza Editorial, 1983.

GONDRA, José Gonçalves e SCHNEIDER, Omar (Orgs.). Educação e instrução nas províncias e na corte imperial (Brasil, 1822-1889). Vitória: EDUFES, 2011.

HILL, Christopher. Origens intelectuais da revolução inglesa. São Paulo: Martins Fontes, 1992.

HUNT, Lynn. A invenção dos direitos humanos. São Paulo: Companhia das Letras, 2009.

LOURENÇO FILHO, M. B. Introdução ao estudo da escola nova. São Paulo: Melhoramentos, 1974.

QUIJANO, Aníbal. Colonialidade do poder, eurocentrismo e América Latina. In: LANDER, Edgardo (Org.). A colonialidade do saber: eurocentrismo e ciências sociais. Perspectivas latino-americanas. Buenos Aires: CLACSO, 2005.

. Cuestiones y Horizontes. Antologia Esencial de la dependência histórico/estructural a la colonialidad/decolonialidad del poder. Buenos Aires: CLACSO, 2014.

RENAN, Ernest. Que é uma nação? Plural: sociologia, USP, São Paulo, 4:154-175, $1^{\text {o }}$. semestre de 1997.

SAID, Edward W. Orientalismo: o Oriente como invenção do Ocidente. São Paulo: Companhia das Letras, 2007.

VEIGA, Cynthia Greive. Escola de alma branca: o direito biológico à educação no movimento da Escola Nova. Educação em Revista. Belo Horizonte: Autêntica, número especial, set. 2000 .

. História da Educação. São Paulo: Ática, 2007.

. "Promiscuidade de cores e classes": tensões decorrentes da presença de crianças negras na história da escola pública brasileira. In: FONSECA, Marcus Vinicius; BARROS, Surya Aaronovich Pombo de (Org.). A História da Educação dos negros no Brasil. Niterói: Eduff, 2016a.

. Trabalho infantil e escolarização: questões internacionais e o debate nacional (1890-1944). Revista Brasileira de História da Educação. V. 16, n. 4 [43], 2016b.

- Crianças pobres como grupo outsider e a participação da escola. Educação \& Realidade, Porto Alegre, v. 42, n. 4, p. 1.239-1.256, out./dez. 2017. http://dx.doi. org/10.1590/2175-623664210

VIDAL, Diana Gonçalves, SÁ, Elizabeth Figueiredo e, SILVA, Vera Gaspar da (Orgs.). Obrigatoriedade escolar no Brasil. Cuiabá: UFMT, 2013. 


\section{DOCUMENTOS}

A REPÚBLICA, Espírito Santo, 28/07/1902, p. 1.

ALBUM LITTERARIO. Periódico Instructivo e Recreativo. Ano II, n. 15, 15/03/1861.

ANNAES do II Congresso Brasileiro de Instrucção Primária e Secundaria. Belo Horizonte: Imprensa Official, 1912.

COUTO, Miguel. No Brasil só há um problema nacional: a educação do povo. Rio de Janeiro: Typ. Do Jornal do Commercio, 1927.

REVISTA ESCOLAR. Redator Dr. Thomaz da Silva Brandão, Ouro Preto, 1889.

RELATORIO que à Assembléa Legislativa Provincial de Minas Geraes apresentou na Sessão Ordinária de 1873 o presidente da Província Venancio José de Oliveira Lisboa. Ouro Preto: Typografia de J. F. de Paula Castro, 1873.

\section{SOBRE A AUTORA}

\section{Cynthia Greive Veiga}

Doutora em Ciências Humanas, área História (UNICAMP). Professora titular da Faculdade de Educação da Universidade Federal de Minas Gerais. Bolsista Produtividade de Pesquisa - CNPq- 1C.

Submetido em: 26-6-2017

Aceito em: $23-2-2018$ 